\title{
The Great Robotics Debate
}

\author{
Are robots and automation destroying more jobs than they are creating?
}

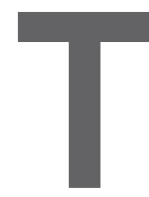

HE FIELD OF artificial intelligence has been accompanied by a vigorous debate essentially from its very beginnings. Alan Turing addressed the issue of machine intelligence in 1950 in what is probably his most well known paper, "Computing Machinery and Intelligence," where he proposed the "Imitation Game," now known as the "Turing Test," as an operational definition for machine intelligence. The main focus of the paper is the possibility of machine intelligence. Turing carefully analyzed and rebutted arguments against machine intelligence and stated, "I believe that at the end of the century the use of words and general educated opinion will have altered so much that one will be able to speak of machines thinking without expecting to be contradicted." This view was later strenuously contested by philosophers such as Hubert Dreyfus and John Searle, who argued against the possibility of intelligent machines.

Many of the early AI pioneers were also brimming with unbounded optimism. Marvin Minsky wrote in 1967: "Within a generation...the problem of creating 'artificial intelligence' will substantially be solved." Perhaps because of such overoptimism, AI has suffered from repeated "AI Winters": periods that were characterized by slow progress and a dearth of research funding. AI researchers refer to the "First AI Winter," 1974-1980, and “Second AI Winter," 1987-1993.

More recently a major debate has erupted among economists regarding the impact of robots and automation on jobs and the possibility of technological unemployment. The traditional approach by economists is skeptical of Luddism - the fear of the inevitable changes brought about by new technology. Such a position was expressed by Kenneth Rogoff, who wrote last year, "Since the dawn of the industrial age, a recurrent fear has been that technological change will spawn mass unemployment. Neoclassical economists predicted that this would not happen, because people would find other jobs, albeit possibly after a long period of painful adjustment. By and large, that prediction has proven to be correct." But in a recent working paper, "Smart Machines and Long-Term Misery," Jeffrey Sachs and Laurence Kotlikoff posed the question, "What if machines are getting so smart, thanks to their microprocessor brains, that they no longer need unskilled labor to operate?" After all, they point out, "Smart machines now collect our highway tolls, check us out at stores, take our blood pressure, massage our backs, give us directions, answer our phones, print our documents, transmit our messages, rock our babies, read our books, turn on our lights, shine our shoes, guard our homes, fly our planes, write our wills, teach our children, kill our enemies, and the list goes on."

It is in the context of the Great Recession that people started noticing that while machines have yet to exceed humans in intelligence, they are getting intelligent enough to have a major impact on the job market. In his 2009 book, The Lights in the Tunnel: Automation, Accelerating Technology and the Economy of the Future, Martin Ford asked: "What economic impact will technological acceleration have as we anticipate recovery from the current crisis-and in the years and decades ahead?" In their 2011 book, Race Against The Machine:
How the Digital Revolution is Accelerating Innovation, Driving Productivity, and Irreversibly Transforming Employment and the Economy, Erik Brynjolfsson and Andrew McAfee argued that "technological progress is accelerating innovation even as it leaves many types of workers behind."

It is only this year that this debate moved from economics to computer science. In an interview with Steven Cherry earlier this year for IEEE Spectrum's Techwise Conversations, I argued that "by 2045 machines will be able to do if not any work that humans can do, then a very significant fraction of the work that humans can do" (http://spectrum.ieee. org/podcast/at-work/tech-careers/thejob-market-of-2045), and wondered whether we are ready for a world in which half the adult population does not work. In a follow-up interview, Henrik Christensen, a Georgia Tech professor of robotics, disagreed and argued that automation is still creating more jobs than it destroys (http:// spectrum.ieee.org/pod-cast/robotics/ industrial-robots/robots-are-not-killingjobs-says-a-roboticist).

This is a fundamental debate. Robotics is clearly going to be a key economic enabler, as declared in the recent report "Roadmap for U.S. Robotics," perhaps as transformative as the Internet, but will its fruits be distributed equitably or will it create classes of haves and have-nots? We are launching this debate in the pages of Communications with this editorial and a Viewpoint article by Martin Ford (p. 37). I view this discussion as one of the most important our community needs to engage in, and I hope to see a robust conversation.

Moshe Y. Vardi, EDITOR-IN-CHIEF 